
25 Research Square
Preprints are preliminary reports that have not undergone peer review.
They should not be considered conclusive, used to inform clinical practice,
or referenced by the media as validated information.

\title{
The Work-Related Stress Experienced by Registered Nurses at Municipal Aged Care Facilities: A Qualitative Content Analysis
}

\author{
Cilmara Arén \\ School of Health and Welfare, Dalarna University, Falun, Sweden \\ Ingrid From ( $\nabla$ ifr@du.se) \\ School of Health and Welfare, Dalarna University, Falun, Sweden \\ Armand Jaçelli \\ School of Health and Welfare, Dalarna University, Falun, Sweden \\ Berit Gesar \\ School of Health and Welfare, Dalarna University, Falun, Sweden
}

\section{Research Article}

Keywords: Experiences, nursing care, older people, registered nurse, work-related stress

Posted Date: January 7th, 2022

DOI: https://doi.org/10.21203/rs.3.rs-1208710/v1

License: (c) (1) This work is licensed under a Creative Commons Attribution 4.0 International License. Read Full License 


\section{Abstract \\ Background}

Stress can originate from many different unsatisfying work situations. Registered nurses working in municipal care have experience of work-related stress in different ways.

Aim

The purpose of this study was to describe the work-related stress experienced by registered nurses caring for older people at municipal aged care facilities.

\section{Methods}

Qualitative semi-structured interviews according to Polit and Beck were carried out in clinical work at six different municipal aged care facilities in Sweden. Twelve registered nurses participated in the study.

\section{Results}

The results outlined in one main central theme: Feelings of inadequacy and dissatisfaction contribute to work-related stress and three categories: Difficulty coping with work tasks, Insufficient support, Work-related stress affects private lives. Areas identified were lack of time, staff shortages, high number of patients, lack of communication and teamwork in the working group, showing that inadequacy and dissatisfaction can contribute to workrelated stress. This can contribute to work-related stress, and it can be a result of problems in the organizational and social work environment.

\section{Conclusion}

This study showed the everyday experiences of registered nurses' stress at work. The reasons that registered nurses experience a heavy workload were found to be similar in several municipal care facilities. Future interventions should consider the areas of stress found in this study in order to reduce the risk of further increasing the work-related stress experienced by registered nurses working in municipal aged care.

\section{Background}

The World Health Organization, WHO (2017) has classified stress as the "health epidemic of the 21st century" and stated that work-related stress is the reaction that people may have when presented with work demands and pressures beyond their experience and capabilities. Personal stress arises in a wide range of work situations when employees feel they haveinsufficient support from managers and colleagues and inadequate control over work processes (1). Stressors of emotional or physical tension are described by Yao et al. (2) as any event or thought that trigger people to feel frustrated, angry, or nervous.

Previous research points out that registered nurses working in municipal care had different work-related stressors, such as workload, that impact on physical and mental well-being $(3,4)$. Understaffing and the lack of good working relationships between colleagues or having less experience all affect your mental health $(3,5)$. Lack of support from management in emergency care caused many negative effects, such as the decreased quality of patient care and safety as well as being rushed (6). Besides, Fang et al. (7) describe how registered nurses who feel a significant commitment to their work can become too committed, which leads to increased work-related stress. Work-related stress was the biggest contributor to poor work satisfaction. According to Hassan et al. (8) and van Steijn et al. (9), work-related stress is an increasing cause of work-related diseases and injury among healthcare workers.

The organization of care of older people in a local municipality is complex and may cause stress (10). One stress factor is working conditions where there is a high risk of reduced quality of care and work-related stress diseases for the registered nurses. Work-related stress in Europe is an increasing problem which, according to Baye et al. (11), is associated with non-functioning working units and work on rotation. Anshasi et al. (12) described the fact that there is a significant need for competence development in older people's care among nursing staff in the municipal care facilities. To improve an employee's health-related quality of life without stress, it is essential to develop intervention programs (13).

Work-related stress among registered nurses raises significant concerns about patient safety as well as nurses' attitudes to their patients in nursing homes and aged care facilities and quality of aged care $(14,15)$. The lack of time can contribute to the work sometimes being carelessly done, which can lead to an increased risk of making serious mistakes (16). People perceive and handle stressful situations in different ways. This is because humans are different and experience things differently (16). Stress can bring out different abilities in different people in order to cope with stressful situations. Some people may experience stressful threatening experiences as challenges. These challenging situations can cause some people to feel anxiety for another person it can lead to feeling excited in a positive way. Bittinger et al. (17) describe work stress as dangerous and harmful for registered nurses and counteracting this may be the key to reducing the negative effects of stress on an individual, leading to better patient care, and avoiding nurses becoming overworked. 
Study coping strategies is the key to decreasing the adverse effects of stress on an individual, leading to better patient care and avoiding overwork.

When registered nurses cannot provide satisfactory patient care because lack of time, resources, and work-related stress it can result in them becoming overworked and reduced their quality of life (16). Furthermore, studies have shown that a long period with a heavy workload can cause many other negative impacts, such as critical incidents, or high staff turnover among registered nurses $(14,15)$.

According to Antonovsky (18) the experience of feeling connected, the Sense of Coherence, determines what degree of mental health the individual can feel. In the demand-control-support model by Karasek and Theorell (1990), they describe the relationship between health and working life stress. This model shows which conditions in the work environment can decrease stress. The main concepts are demand, control, and social support. The authors emphasize the importance of a social network in reducing work-related stress and how it can help to reduce the risk of illness in the workplace (19).

Staff shortages and understaffing in nursing are problematic and can negatively affect the quality of care. Although it is difficult to eliminate stress, the goal is to keep work-related stress as low as possible, not to become harmful to the registered nurse. Nurses should have satisfactory working conditions and therefore it is essential to identify sources of stress affecting registered nurses (20). With more and more of the world's population suffering from work-related stress conditions, there is a need to be more proactive in reducing work-related stress (1).

Work-related stress for a registered nurse has proven to be a danger to patient safety and quality of care as well as to the nurse's own physical or mental well-being and it can lead to them becoming overworked and a decreased quality of life. The working environment and workplace management might be unsatisfactorily organized and lead to a poor job satisfaction. Work-related stress and overwork among registered nurses are increasingly recognized as significant threats to patient safety and quality of care. Clinical activities that fall under the direction of registered nurses with work-related stress and overwork can lead to unfinished patient follow-up and aftercare plans. With more and more of the world's population suffering from work-related stress conditions, it is essential to study nurses' experiences of work-related stress. According to our knowledge, there are few studies focusing on stress among nurses in municipal care.

\section{Aim}

The purpose of this study was to describe the registered nurses' experiences of work-related stress in the care of older people at municipal aged care facilities.

\section{Method}

\section{Design}

This study was an empirical qualitative study based on semi-structured interviews (21). The data was analyzed with qualitative content analysis according to the description by Graneheim and Lundman (22).

\section{Sample selection}

The selection of participants was made using convenience sampling (21). Inclusion criteria for the participation in the study were that the registered nurses should have worked for at least one year or more in aged care facilities. No criteria for exclusion were applied. The sample consisted of twelve registered nurses, seven women and five men, aged from 25-70 years old, and seven of them had advanced nurse practitioner education. Were carried out in clinical work at six different municipal aged care facilities in Sweden. Before starting the interviews', written information was provided, and a written consent form was signed by the manager of the respective facility. After consideration, the interested registered nurses contacted the authors and accepted participation by signing and returning a letter of consent to the authors.

\section{Data collection}

The interviews were carried out at the participant's workplace. All the participants in the study were informed that they could discontinue the participation at any time without stating the reason. The questions were about stress situations at work and covered their daily work in general but also more detailed discussions of when and why stressful situations occurred and how they handled them. All participants had the experience of working in the care of older people at municipal care facility with 1-40 years' experience of the nursing profession. All interviews were conducted in Sweden, in March 2021 . Informed consent was obtained, both orally and in writing, before the start of the interview. The individual interviews lasted about $40-45$ minutes and were recorded using a digital voice recorder. The recorded material was transcribed verbatim.

\section{Data analysis}

The method of qualitative content analysis used was according to Graneheim and Lundman (22). As described by Polit and Beck (21) a transcript must be accurate and fully reflect the content of the interview. The content was divided into areas based on the respective research questions. The interviews were read several times by both authors and transcribed into text. Parts of the content that were related to the aim were set as meaning units which were then condensed and coded. The codes were compared to identify and describe variations and similarities in the textual content to answer the aim of the study. 
To ensure the credibility of the codes, they would be checked against condensations and meaning units. Then the codes would be sorted into categories based on similar content, and these categories would be analysed to answer the aim of this study. The data were analyzed through a qualitative content analysis at both manifest and latent levels which was in accordance with Graneheim and Lundman (22).

This study was approved by the ethics committee at Dalarna University:

HDa dnr 7.1.1 $2021 / 159$.

\section{Results}

The result describes the registered nurses' experiences of work-related stress. The analysis resulted in one central theme "Feelings of inadequacy and dissatisfaction contribute to work-related stress"three categories and ten subcategories that responded to the study's purpose. See an overview in table 2.

Feelings of inadequacy and dissatisfaction contribute to work-related stress

The results indicated that the registered nurses experienced different types of work-related stress. The main theme "Feelings of inadequacy and dissatisfaction contribute to work-related stress " was divided into three categories: Difficulty coping with their work tasks, Insufficient support, and Workrelated stress affects private lives.

\section{Difficulty coping with work tasks}

Some of the difficulties connected to coping with their work were according to the registered nurses: Lack of time, Understaffing, Lack of control, Difficulties in prioritizing work, Heavy workload.

\section{Lack of time}

The participants described that they did not have enough time and resources to keep up with everything that should be done. Meanwhile, the number of patients was not decreasing, and there were always people in need of care. According to the participants, stress meant not having time to do the things they needed to do and sometimes they needed to be done quickly, depending on the situation. This problem was described as a new kind of stress that may not be there initially, but this was caused by a consistent lack of time.

"I may have to be fast depending on what happens to the patient and then I might feel further stress that was not there earlier" (Interviewee n.6).

\section{Understaffing}

The participants experienced too few staff in relation to the number of work duties and patients, which contributed to stress at work. They described the fact that they were understaffed, and it appeared that they were worried about not being able to do their work satisfactorily. Understaffing made them feel inadequate because they had more to do than they could handle. They described how the understaffing put tremendous pressure on them, leading to a more significant amount of stress.

"We are very... very understaffed and at the same time we have new nurses who should get the right introduction, they should have the right support" (Interviewee n.3).

\section{Lack of control}

The participants describe the lack of control as one of the causes which increased stress among them. The participants felt having no control over their work. They had no autonomy in the workplace, and this could likely lead to work-related stress. Nevertheless, there were times when the participants felt that they lost control, and not having control for them meant doing things more slowly, because they felt that the tasks needed more time or not having a plan B in the event of unexpected incidents.

"Everything that you feel that you do not have control over can create stress" (Interviewee n.2).

\section{Difficulties in prioritizing work}

Participants said they felt they had to prioritize in the workplace constantly as the workload increased and eventually, that could lead to decreased patient safety. Every time they had to prioritize, they experienced this as a stressful situation because they felt that they had not done enough for the patients and their relatives.

"We are nurses we are not superhumans" (Interviewee n.9).

The participants described how learning to prioritize goes beyond knowing how to use time properly. Making the wrong choice when prioritizing and planning can be problematic and be stressful. The participants said person-centered care should be prioritized to a greater extent to reduce stress in the workplace.

"Learning to prioritize can reduce stress. To do one thing at a time" (Interviewee n.10). 


\section{Heavy workload}

The participants described how they had a large amount of work during a workday, which lead to increased stress. The results showed that participants who experienced a high workload and stress level at their workplace could have increased dissatisfaction with their work and either changed their place of work or left the profession, which increased the workload for those who remained.

"Work-related stress is for me a large amount of work no matter what the work procedures or the mental pressure are" (Interviewee n.3).

\section{Insufficient support}

Insufficient support described how the participants experienced stress and what work-related stress meant to them. Their responses were divided into three subcategories: Insufficient team collaboration, Insufficient knowledge and training, Insufficient management support.

\section{Insufficient team collaboration}

The registered nurses felt that the physicians' work in the care team was insufficient, and this could contribute to experiences of work-related stress. It also emerged that the participants experienced difficulties contacting a physician and getting a response. They needed to call the doctor several times so they could get advice about a particular patient. This situation was stressful because participants described cases when there was urgent to get in touch with a physician and they could not.

"Then it can be stressful if you need a consultation from a doctor. You call them several times and no feedback. It can also be stressful" (Interviewee n.12).

The participants described how support and cooperation between colleagues needed to be improved. They outlined the importance of competence and the cooperation between the various healthcare providers to work towards the same goal.

\section{Insufficient knowledge and training}

The participants revealed that working with patients made them doubt their professional nursing skills. Some of the participants mentioned that they wanted further education in their profession in order to be more proactive and feel confident in their work. The amount of work overload and the responsibility for other nursing staff with insufficient knowledge made them feel stressed, and the participants made clear that, this was a cause of workrelated stress.

"This uncertainty about their skills. I have no further education to lean on. I would like that. This too this is not going to be good. Even if you try" (Interviewee n.11).

\section{Insufficient management support}

From the interviews, it emerged that the participants experienced a lack of support from the management, which contributed to an increased feeling of stress among them. According to the registered nurses, some of the managers did not have a degree in nursing, and they did not understand the nurse's perspective or know what the role or the duties of the registered nurse. The participants described how it was important to have a manager who was on site, empathetic and was willing to find compromises with the registered nurses. According to the participants, this could help to reduce work-related stress. The participants said that a supportive management could lead to less stress being perceived as less among the registered nurses.

"Cooperation with the manager is important" (Interviewee n.3).

\section{Work-related stress affects private lives}

In this category, participants described how the registered nurses experienced stress and how it affected their private life daily. In addition, they also talked about how their private life was affected in relation to the ongoing covid-19 pandemic. The two subcategories were: Impact of work-related stress on the nurses' private livesand Impact of the pandemic on nurses' private lives

\section{Impact of work-related stress on the nurses' private lives}

The participants reported feeling tired and sometimes irritated, and they described how this could also affect their quality of life. The participants described how working as a registered nurse was often stressful. They perceived that stress at work caused negative consequences for both physical and psychosocial well-being. Fatigue was experienced as a significant problem for the participants. It was noticeable during working hours, but it also affected the person in their spare time. The participants described how they felt fatigued, drained of energy, and they often did not remember things, which frightened them. They felt there was a lot of stress at work. For some of them, it felt as if it could be challenging to maintain a professional approach at work, and they tried to hide their feelings and to do the best for the patient or the relatives of the patient, but it was difficult to do. Meanwhile, they described how this mix of feelings also affected the quality of their own life.

"I get tired, tired in my body, tired in my head, tired in general... I get gloomy" (Interviewee n.2). 
During the period when the interviews were conducted, a situation arose that had not existed before, and which led the participants feeling more stress. The situation was Covid-19, and it has changed how everyone works. During a pandemic situation, there was added stress. The participants had significant concerns about the risk of being exposed to the disease at work or even spreading it to loved ones, but they were also uncertain about the future in their workplace. It was a dilemma that created working-related stress among the registered nurses in municipal care. For the participants, this new stressful environment, and the constant stream of new guidelines every week during the outbreak of Covid-19 led to high work-related stress for the registered nurses. As a result, the workload became heavier, and the amount of stress increased. During the interviews, they also revealed that many and constant changes to rules and recommendations made the healthcare providers feel even more stressed about not having control over their work.

"It was a day when everything really exploded at once, I got a call related to the Covid-19 epidemic and there was one person who was infected and then within a quarter of an hour there was another who was infected, and all hell broke loose at once and everything had to be done now" (Interviewee n.4).

\section{Discussion}

Experiences of work-related stress of registered nurses working in in municipal aged care facilities can be cause by problems in the organizational and social work environment. The registered nurses described that stress occurred as they had "Difficulties coping with their work task" and they could not perform their duties. These findings are in line with White et al. (16) who pointed out that lack of time contributed to dissatisfaction at work, which also significantly increases the risk of threats to patient safety and quality of care. The registered nurses in this study described that understaffing forced them to more duties than they could handle. The risk of decreased quality of care because of understaffing in nursing was also brought up by Semachew et al.(20) and entails inevitable, negative consequences, especially for the quality of care and work satisfaction among registered nurses.

The registered nurses in this study described the difficulties of prioritizing what needed to be done the most at work because they had difficulties coping with so many work tasks. They described feeling a lack of control because of the lack of time and heavy workload caused of lack of support from the management, which in turn leads to increased stress. The demand-control-support model by Karasek and Theorell (19) displays conditions at work that predispose work-related stress and it was stated in this study that it was essential to have an empathetic manager present who was able to understand them. The registered nurses also talked about the fact that they had a lot of work, which lead to increased stress.

The registered nurses in our study experienced that the communication in the team suffered when the registered nurses experienced work-related stress and that it had a negative effect on the patient care. The demand-control-support provides that in a culture for preventing work-related stress, it is essential to have social support to fulfill the work tasks. Dagget et al. (23) also described that not enough support from management could lead to difficulties in workers doing their job properly and eventually increase the work-related stress among the health care providers. The registered nurses in our study who experienced a heavy workload and stress were considering quitting their job. These findings have similarities with previous studies by Carlesi et al. (14) and Chiang et al. (15), who showed that registered nurses left their jobs due to work-related stress and work-related fatigue and because of the inferior quality of patient care. According to Karasek and Theorell (19), it is essential to have control over the work situation in order to feel good at work. The findings suggest that if nurses felt as if they had more support and understanding from management, then their work-related stress may be reduced. This seems challenging due to limited support from both management and colleagues.

The findings in this study showed that not having control over the work and communication problems were stressful. In concordance to the study of Josefsson (2012), the organization must function in a way that creates conditions for registered nurses to perform risk free care for older people. Routines must be clear and unequivocal (6). The stressful work situation described by the participants in this study contributes to sleeping difficulties. The tiredness could lead to source of irritation and could also negatively affect the quality of life of the nurses and risk patient safety. Fatigue and sleeping disorders were experienced as problematic. Previous research provides work-related problems from stress such as neck disorders, sleep disorders, headache, and fatigue and how they affect the quality of life of registered nurses (6). Nowrouzi et al. (13) argue that improving an employee's health-related quality of life without stress, intervention programs must be incorporated in the context of each ward. These programs should focus on promoting social support, sleep quality, exercise, and managing? smoking habits. During the interviews, the registered nurses experienced more workrelated stress than usual due to the covid19 pandemic. According to the participants, Covid19 has changed how they work in some situations and has led to more stress among these participants. The major concerns were about the risk of being exposed to the disease at work and managing various incidents at the workplace. The pandemic situation led to frustration and feelings of not doing the work satisfactorily. Antonovsky (18) argues that what is essential for the mental health of an individual is dealing with reactions to stress.

\section{Method discussion}

The study was based on a qualitative approach and was performed using individual interviews with the participants. This method was chosen because the authors were interested in investigating subjective experiences of work-related stress in the care of older people in municipal aged care facilities. The choice of method is supported by Polit and Beck (21) who describe that qualitative method is suitable for studying people's experiences, behaviors, and feelings therefore this method was chosen for this study. The reason why a semi-structured interview was chosen instead of, for example, a structured interview was to get a deeper insight into the phenomenon. The study's credibility refers to the extent to which research is trustworthy in the data collection and analysis. To prove this, each step in the method was described, and examples of how the analysis was performed were illustrated in the method section. Before starting the interviews, all the informants received information regarding the purpose of the study, the approach, and how confidentiality would be managed and that they could discontinue their participation at any time if they wished. This information was given both in writing and orally (24). The study included both women and men. The registered nurses who participated had a good age distribution and different 
lengths of work experience within municipal care and inpatient care. This could also be seen as a strength in the study. Regarding the dependability of the study, the focus has been on the participants' experiences of work-related stress. The data collection was done through the help of an interview guide, and the interviews were recorded by the authors with a digital voice recorder. All interviews were transcribed and translated into English. Answers that were unclear or could be interpreted in several ways were listened to a few times to get a clearer understanding of their statements.

According to Polit \& Beck (21) dependability is about the fact that the study can be replicated with similar informants, with similar conditions, and get similar results. In qualitative research, it is also important to discuss confirmability during the study. The authors have been faithful and transparent that all the data obtained during the interviews are original and no data has been modified to change meaning. However, in qualitative studies, it is difficult to completely achieve confirmability as a researcher. However, striving for confirmability should be the ambition for all authors in qualitative research (22)

This manuscript was written during a pandemic outbreak. During the interviews, the registered nurses described the Covid-19 pandemic as a situation that added more stress to their daily work, which changed the way of working.

\section{Conclusions}

By interviewing registered nurses working in aged care, their experience of work-related stress can provide increased knowledge about care and stress management. A better understanding of the reasons for work-related stress may enable registered nurses to take the necessary steps to minimize or even prevent stress. Stress can cause high levels of sick leave and if stress levels can be reduced this study may contribute lower levels of sick leave and as a result better cost-efficiency for the employer. To achieve this, management must intervene and create strategies to prevent work-related stress among healthcare providers.

In this study, experiences of work-related stress among a number of registered nurses were described and factors contributing to stress identified. Better collaboration in the care team and having an understanding manager is of great importance for reducing work-related stress. When the registered nurses who experienced stress received support to help deal with their situation, better conditions were created in order to provide a meaningful everyday life for the individual. With more and more of the world's population suffering from work-related stress conditions, we must all be more proactive in reducing work-related stress.

The study can provide a basis for further research about work-related stress experienced by registered nurses in the care of older people at municipal aged care facilities. Future interventions should focus on introducing new and effective strategies for managing stress in the workplace and if possible, on a larger scale.

\section{Abbreviations}

WHO

The World Health Organization

\section{Declarations}

\section{Ethics approval and consent to participate}

This study was approved by the ethics committee at Dalarna University: HDa dnr 7.1.1 2021/159. Written informed consent was obtained from all participants. All methods were carried out in accordance with relevant guidelines and regulations. In this study, ethical considerations such as obtaining an informed consent form from every participant, and the principles of confidentiality and anonymity were observed. Furthermore, all the participants in the study were informed that they could discontinue the participation at any time without stating the reason.

\section{Consent for publication}

Not applicable.

\section{Availability of data and materials}

The datasets used and/or analysed during the current study are available from the corresponding author on reasonable request.

\section{Competing interests}

The authors declare that they have no competing financial conflicts of interest.

\section{Funding}

Not applicable.

\section{Authors'contributions}


All the authors have contributed equally to all parts of this master's thesis paper. All authors have read and approved the manuscript. As well, their thanks go to all nurses participating in this study. All authors read and approved the final manuscript.

\section{Acknowledgments}

Not applicable.

\section{References}

1. World Health Organization. Occupational health. [Internet]. Geneva: World Health Organization; 2017. [cited 2019 Dec 01] Available from: https://www.who.int/news-room/fact-sheets/detail/protecting-workers'-health.

2. Yao XY, Shao J, Wang LA, Zhang J, Zhang C, Lin YJ. Does workplace violence, empathy, and communication influence occupational stress among mental health nurses? Int J Ment Health Nu. 2021;30(1):177-88.

3. Juthberg C, Eriksson S, Norberg A, Sundin K. Perceptions of conscience, stress of conscience and burnout among nursing staff in residential elder care. Journal of Advanced Nursing. 2010;66(8):1708-18.

4. Schmidt KH, Diestel S. Job demands and personal resources in their relations to indicators of job strain among nurses for older people. Journal of Advanced Nursing. 2013;69(10):2185-95.

5. Khamisa N, Peltzer K, Ilic D, Oldenburg B. Work related stress, burnout, job satisfaction and general health of nurses: A follow-up study. Int J Nurs Pract. 2016;22(6):538-45.

6. Josefsson K. Registered nurses' health in community elderly care in Sweden. Int Nurs Rev. 2012;59(3):409-15.

7. Fang L, Hsiao LP, Fang SH, Chen BC. Associations of work stress and humor with health status in hospital nurses-A cross-sectional study. J Clin Nurs. 2019;28(19-20):3691-9.

8. Hassan NM, Abu-Elenin MM, Elsallamy RM, Kabbash IA. Job stress among resident physicians in Tanta University Hospitals, Egypt. Environ Sci Pollut R. 2020;27(30):37557-64.

9. van Steijn ME, Scheepstra KWF, Yasar G, Olff M, de Vries MC, van Pampus MG. Occupational well-being in pediatricians-a survey about work-related posttraumatic stress, depression, and anxiety. European Journal of Pediatrics. 2019;178(5):681-93.

10. Gustafsson C, Fagerberg I, Asp M. Supportive leadership in Swedish community night nursing. J Nurs Manage. 2010;18(7):822-31.

11. Baye Y, Demeke T, Birhan N, Semahegn A, Birhanu S. Nurses' work-related stress and associated factors in governmental hospitals in Harar, Eastern Ethiopia: A cross-sectional study. Plos One. 2020;15(8).

12. Anshasi HA, Fawaz M, Alhalalmeh S, Ahmad WQ, Tassi A. Nurses' stressors and their quality of life: A study on nurses caring for older patients. Nurs Open. 2020;7(6):1698-706.

13. Nowrouzi B, Giddens E, Gohar B, Schoenenberger S, Bautista MC, Casole J. The quality of work life of registered nurses in Canada and the United States: a comprehensive literature review. Int J Occup Env Heal. 2016;22(4):341-58.

14. Carlesi KC, Padilha KG, Toffoletto MC, Henriquez-Roldan C, Juan MAC. Patient Safety Incidents and Nursing Workload. Rev Lat-Am Enferm. 2017;25.

15. Chiang HY, Hsiao YC, Lee HF. Predictors of Hospital Nurses' Safety Practices Work Environment, Workload, Job Satisfaction, and Error Reporting. J Nurs Care Qual. 2017;32(4):359-68.

16. White EM, Aiken LH, McHugh MD. Registered Nurse Burnout, Job Dissatisfaction, and Missed Care in Nursing Homes. Journal of the American Geriatrics Society. 2019;67(10):2065-71.

17. Bittinger AC. Relationship Between Emotional Intelligence and Occupational Stress Levels Among Certified Registered Nurse Anesthetists. AANA Journal. 2020;88(5):398-404.

18. Antonovsky A. Hälsans mysterium (in Swedish). 2nd ed. Stockholm: Natur och kultur; 2005.

19. Karasek RAT, T. Healthy work: stress, productivity, and the reconstruction of working life. New York: Basic Books; 1990.

20. Semachew A, Belachew T, Tesfaye T, Adinew YM. Predictors of job satisfaction among nurses working in Ethiopian public hospitals, 2014: institution-based cross-sectional study. Hum Resour Health. 2017;15.

21. Polit DF, Beck C. Nursing Research: Generating and Assessing Evidence for Nursing Practice. 10th ed. Philadelphia: Wolters Kluwer; 2017.

22. Graneheim UH, Lundman B. Qualitative content analysis in nursing research: concepts, procedures and measures to achieve trustworthiness. Nurs Educ Today. 2004;24(2):105-12.

23. Dagget T, Molla A, Belachew T. Job related stress among nurses working in Jimma Zone public hospitals, South West Ethiopia: a cross sectional study. Bmc Nurs. 2016;15.

24. World Medical A. World Medical Association Declaration of Helsinki: ethical principles for medical research involving human subjects. JAMA. 2013;310(20):2191-4.

\section{Tables}


Table 1. Examples of meaning units, condensed meaning units and codes.

\begin{tabular}{|c|c|c|}
\hline Meaning units & Condensed meaning & Codes \\
\hline $\begin{array}{l}\text { Then you can get physical problems such as, gastritis or palpitations or that you } \\
\text { sweat or something and you feel stressed. }\end{array}$ & $\begin{array}{l}\text { Stress can cause various physical } \\
\text { problems such as gastritis, } \\
\text { palpitations, or sweating. }\end{array}$ & $\begin{array}{l}\text { Stress can cause } \\
\text { physical } \\
\text { problems. }\end{array}$ \\
\hline $\begin{array}{l}\text { There is also a stress and pressure, and you have patient safety and must prioritize as } \\
\text { the managers say prioritize, prioritize and it is difficult and what should we prioritize } \\
\text { when we have our system that the municipality has established. }\end{array}$ & $\begin{array}{l}\text { Stress and pressure, patient safety, } \\
\text { managers say prioritize, but the } \\
\text { municipality has established a } \\
\text { system. }\end{array}$ & $\begin{array}{l}\text { Stress due to } \\
\text { prioritization } \\
\text { during low } \\
\text { staffing periods. }\end{array}$ \\
\hline
\end{tabular}

Table 2. Overview of central theme, categories, and subcategories.

\begin{tabular}{|c|c|c|c|c|c|c|c|c|c|c|}
\hline \multirow{2}{*}{$\begin{array}{l}\text { Theme } \\
\text { Categories } \\
\text { Subcategories }\end{array}$} & \multicolumn{10}{|c|}{ Feelings of Inadequacy and dissatisfaction contribute to work-related stress } \\
\hline & \multicolumn{5}{|c|}{ Difficulty coping with work tasks } & \multicolumn{3}{|c|}{ Insufficient support } & \multicolumn{2}{|c|}{$\begin{array}{l}\text { Work-related stress } \\
\text { affects private lives }\end{array}$} \\
\hline Subcategories & $\begin{array}{l}\text { Lack } \\
\text { of } \\
\text { time }\end{array}$ & Understaffing & $\begin{array}{l}\text { Lack } \\
\text { of } \\
\text { control }\end{array}$ & $\begin{array}{l}\text { Difficulties } \\
\text { in } \\
\text { prioritizing } \\
\text { work }\end{array}$ & $\begin{array}{l}\text { Heavy } \\
\text { workload }\end{array}$ & $\begin{array}{l}\text { Insufficient } \\
\text { team } \\
\text { collaboration }\end{array}$ & $\begin{array}{l}\text { Insufficient } \\
\text { knowledge } \\
\text { and } \\
\text { training }\end{array}$ & $\begin{array}{l}\text { Insufficient } \\
\text { management } \\
\text { support }\end{array}$ & $\begin{array}{l}\text { Impact } \\
\text { of } \\
\text { work- } \\
\text { related } \\
\text { stress } \\
\text { on the } \\
\text { nurses' } \\
\text { private } \\
\text { lives }\end{array}$ & $\begin{array}{l}\text { Impact of } \\
\text { the } \\
\text { pandemic } \\
\text { on nurses' } \\
\text { private } \\
\text { lives }\end{array}$ \\
\hline
\end{tabular}

